\title{
Estratégias de ensino da simulação do Suporte Básico de Vida em Enfermagem: Uma revisão integrativa
}

\author{
Teaching strategies for the simulation of Basic Life Support in Nursing: An integrative review \\ Estrategias didácticas para la simulación de Soporte Vital Básico en Enfermería: Una revisión \\ integradora
}

Recebido: 16/07/2021 | Revisado: 21/07/2021 | Aceito: 23/07/2021 | Publicado: 31/07/2021

\author{
Simone Buchignani Maigret \\ ORCID: https://orcid.org/0000-0002-1189-0235 \\ Universidade Estadual Paulista "Júlio de Mesquita Filho", Brasil \\ E-mail: sibuchignani@hotmail.com \\ Michelle Cristine de Oliveira Minharro \\ ORCID: https://orcid.org/0000-0001-7001-5935 \\ Faculdade Marechal Rondon, Brasil \\ E-mail: micrisoliveira@yahoo.com.br \\ Rúbia Aguiar Alencar \\ ORCID: https://orcid.org/0000-0002-6524-5194 \\ Universidade Estadual Paulista “Júlio de Mesquita Filho”, Brasil \\ E-mail: rubia.alencar@unesp.br
}

\begin{abstract}
Resumo
Objetivo: analisar a contribuição do uso da simulação clínica como estratégia para o ensino e aprendizagem do Suporte Básico de Vida na Graduação em Enfermagem. Método: revisão integrativa de 16 artigos na íntegra, disponíveis nas bases de dados LILACS, PubMed Central, SCOPUS, CINAHL, Web of Science, Embase, Cochrane e Scielo. Resultados: dos artigos avaliados, a maioria oriunda de pesquisas quase experimental $(43,75 \%)$, foram desenvolvidos no Brasil (43,75\%), com estratégias de ensino aprendizagem envolvendo simulações com robóticas (com simuladores de alta e média fidelidade), Role Play, palestras, jogo online, curso online, Exame Clínico Objetivo Estruturado (OSCE), simulações cênicas (com pacientes padronizados), Aprendizagem baseada em Problema (PBL) e o Modelo de Aprendizagem Ativa para o Pensamento Crítico (ALMCT). O emprego destas estratégias mostra melhor aprendizagem, desenvolvimento das habilidades psicomotoras, autoconfiança, segurança e trabalho em equipe nos estudantes. Conclusão: a simulação clínica em Suporte Básico de Vida apresenta melhor reconhecimento da parada cardiorrespiratória, compressões torácicas efetivas, desfibrilação precoce, desenvolvimento de competências de manejo clínico avançado, incluindo habilidades de trabalho em equipe e tomada de decisão.

Palavras-chave: Enfermagem; Reanimação cardiopulmonar; Simulação; Ensino em enfermagem; Ensino; Suporte
\end{abstract} Básico de Vida.

\begin{abstract}
Objective: to analyze the contribution of the use of clinical simulation as a strategy for teaching and learning Basic Life Support in Undergraduate Nursing. Method: integrative review of 16 full articles, available in LILACS, PubMed Central, SCOPUS, CINAHL, Web of Science, Embase, Cochrane and Scielo databases. Results: of the evaluated articles, the majority originated from quasi-experimental researches (43.75\%), were developed in Brazil (43.75\%), with teaching-learning strategies involving simulations with robotics (with high and medium fidelity simulators), Role Play, lectures, online game, online course, Objective Structured Clinical Examination (OSCE), scenic simulations (with standardized patients), Problem Based Learning (PBL) and the Active Learning Model for Critical Thinking (ALMCT). The use of these strategies shows better learning, development of psychomotor skills, self-confidence, security and teamwork in students. Conclusion: clinical simulation in Basic Life Support presents better recognition of cardiorespiratory arrest, effective chest compressions, early defibrillation, development of advanced clinical management skills, including teamwork and decision-making skills.
\end{abstract}

Keywords: Nursing; Cardiopulmonary resuscitation; Simulation; Nursing education; Teaching; Basic Support of Life.

\section{Resumen}

Objetivo: analizar la contribución del uso de la simulación clínica como estrategia para la enseñanza y el aprendizaje de Soporte Vital Básico en el Grado en Enfermería. Método: revisión integradora de 16 artículos completos, disponibles en las bases de datos LILACS, PubMed Central, SCOPUS, CINAHL, Web of Science, Embase, Cochrane 
y Scielo. Resultados: de los artículos evaluados, la mayoría provino de investigaciones cuasi-experimentales (43,75\%), fueron desarrollados en Brasil (43,75\%), con estrategias de enseñanza-aprendizaje que involucran simulaciones con robótica (con simuladores de alta y media fidelidad), Role Play, conferencias, juego en línea, curso en línea, examen clínico estructurado objetivo (ECOE), simulaciones escénicas (con pacientes estandarizados), aprendizaje basado en problemas (ABP) y modelo de aprendizaje activo para el pensamiento crítico (ALMCT). El uso de estas estrategias evidencia un mejor aprendizaje, desarrollo de la psicomotricidad, autoconfianza, seguridad y trabajo en equipo en los estudiantes. Conclusión: la simulación clínica en Soporte Vital Básico presenta mejor reconocimiento de paro cardiorrespiratorio, compresiones torácicas efectivas, desfibrilación temprana, desarrollo de habilidades avanzadas de manejo clínico, incluyendo trabajo en equipo y habilidades de toma de decisiones.

Palabras clave: Enfermería; Reanimación cardiopulmonar; Simulación; Educación en enfermería; Apoyo básico de la vida.

\section{Introdução}

A mortalidade por doença cardiovascular isquêmica é a primeira causa de morte no mundo, apesar das políticas de saúde de prevenção das doenças não transmissíveis e os avanços tecnológicos no tratamento (American Heart Association, 2015).

$\mathrm{O}$ atendimento e a realização precoce de Ressuscitação Cardiopulmonar $(\mathrm{RCP})$ à vítima em Parada Cardiorrespiratória (PCR), aumentam as taxas de sobrevivência. Uma RCP bem-sucedida depende da sequência de procedimentos realizados na cadeia de sobrevivência, estabelecida pelo American Heart Association (AHA). O Suporte Básico de Vida (SBV) é considerado o atendimento base em casos de PCR e define a sequência primária de reanimação para salvar vidas (AHA, 2015).

O atendimento a PCR, geralmente, é acompanhado de estresse ao profissional da saúde. A AHA enfatiza a importância da educação continuada como disseminação do conhecimento e rotinas adequadas ao atendimento em PCR, Além de constituir critério de avaliação de qualidade no ensino nas instituições (AHA, 2015).

A simulação é uma das estratégias de ensino mais importante na capacitação dos profissionais da saúde em PCR. Atualizando, aprimorando e reduzindo a distância existente entre o que se ensina na teoria e sua prática (AHA, 2020).

Por meio da simulação, pode-se imitar ou representar um ato ou processo, simples ou complexo. A simulação da prática clínica pode ser definida como estratégia, técnica, processo e ferramenta (Sociedade Brasileira de Cardiologia, 2019). Para implementação, é preciso mais do que simuladores eficazes. É necessário que seu uso seja adequado à metodologia da simulação. E têm por finalidades a educação, a avaliação, a pesquisa e a segurança do paciente, experimentado pelo aluno antes da inserção aos cenários de prática. Além disso, contribui com a melhora da eficácia e da eficiência dos serviços de saúde (Ribeiro, Garbuio, Zamariolli, Eduardo \&Carvalho, 2018).

O conhecimento em Enfermagem e a forma de ensinar os estudantes têm evoluído ao longo dos anos. A evolução da ciência em geral e da tecnologia influenciam a Graduação em Enfermagem e seus docentes a prepararem os alunos para o mercado de trabalho. Neste contexto, a simulação é uma ferramenta de ensino que tem sido difundida no mundo (Kim, 2018).

A evidência científica em simulação demonstra que esta estratégia no ensino aumenta e promove o desenvolvimento de aprendizagens significativas nos estudantes, podendo atingir o seu expoente máximo se os participantes a encararem como legítima, autêntica e realista (Kim, 2018). Existe ainda forte evidência de que os estudantes apreciam a simulação por ser praticada em ambiente seguro e isento de riscos (French, 2020).

No processo de formação das competências busca-se, dentre outros aspectos, desenvolver, no estudante, a capacidade de agir eficazmente no SBV. Assim, colaborar para a articulação dos vários saberes e utilizar o arsenal de conhecimentos na resolução de problemas, no manejo de situações de imprevisibilidade, mobilizando os recursos internos, para enfrentar os desafios do trabalho (Joanna Briggs Institute (IJB), 2014).

Frente ao contexto apresentado, o objetivo deste trabalho é analisar a contribuição do uso da simulação clínica como estratégia para o ensino e aprendizagem do Suporte Básico de Vida na Graduação em Enfermagem. 


\section{Metodologia}

Foi desenvolvida uma revisão integrativa que consiste em um tipo de pesquisa que sintetiza resultados de estudos anteriores, fornece conhecimento profundo e abrangente para responder as questões focadas na prática clínica, possibilitando ao enfermeiro decidir pela melhor conduta a ser tomada (Moher et al., 2000). Ainda oferece o acesso rápido aos resultados relevantes que fundamentam as condutas ou a tomada de decisão, além de verificar lacunas do conhecimento (Mendes et al. 2008).

A construção do presente estudo foi guiada por seis etapas: identificação do tema e elaboração da questão de pesquisa, estabelecimento de critérios de exclusão e inclusão definição das informações a serem extraídas dos estudos selecionados/categorização dos estudos, avaliação dos estudos incluídos na revisão, interpretação e síntese dos resultados, e, por último a apresentação da revisão (Mendes, Silveira \& Galvão, 2008).

Seguindo as recomendações do IJB (2014), foi elaborado o Quadro 1 com os itens: título, objetivo, questão de pesquisa, estratégias de busca, critérios de inclusão, extração e síntese dos dados. Dois pesquisadores realizaram as buscas separadamente e após essa etapa os resultados foram comparados, com o objetivo de minimizar divergências.

Todas as etapas foram alicerçadas em uma estrutura formal e rígida de trabalho que permitiu evidenciar e discutir a simulação clínica no processo de ensino e aprendizagem de Suporte Básico de Vida no Curso de Graduação em Enfermagem.

Quadro 1. Protocolo para realização da pesquisa de revisão integrativa: uso de simulação da prática clínica do Suporte Básico de Vida no Curso de Graduação em Enfermagem.

Título: Simulação da prática clínica do Suporte Básico de Vida no Curso de Graduação em Enfermagem: revisão integrativa

1) Objetivo: analisar a contribuição do uso da simulação clínica como estratégia do ensino e aprendizagem do Suporte Básico de Vida na Graduação em Enfermagem

2) Questão norteadora: Como a simulação da prática clínica tem sido utilizada no processo de ensino aprendizagem no Suporte Básico de Vida no Curso de Graduação em Enfermagem?

3) Estratégias para buscas

3.1. Base de dados

Base de dados 1: LILACS

Base de dados 2: Scielo

Base de dados 3: PubMed

Base de dados 4: CINAHL

Base de dados 5: Scopus

Base de dados 6: Embase

Base de dados 7: Cochrane

Base de dados 8: Web of Science

3.2. Busca pelos descritores e palavras-chave - realizada em março de 2020

Base de dados 1: LILACS

(Validation studies OR estudios de validación OR estudos de validação) AND (nursing OR enfermería OR enfermagem) AND (cardiopulmonary resuscitation OR reanimación cardiopulmonar OR reanimação cardiopulmonar) AND (simulação OR simulation OR simulacion $)=1$ artigo

(Resuscitation OR reanimación cardiopulmonar OR reanimação cardiopulmonar) AND (education, nursing OR educación en enfermería OR educação em enfermagem) $=25$

Base de dados 2: Scielo

(Validation studies OR estudios de validación OR estudos de validação) AND (nursing OR enfermería OR enfermagem) AND (cardiopulmonary resuscitation OR reanimación cardiopulmonar OR reanimação cardiopulmonar) AND (simulação OR simulation OR simulacion $)=1$

(Undergraduate nursing student) AND (nursing) AND (cardiopulmonary resuscitation) AND (basic life support) $=2$

Base de dados 3: PubMed

(Validation study) AND (basic life support) AND (simulation training) AND (nursing education)=1

(Validation studies) AND (nursing) AND (cardiopulmonary resuscitation) AND (simulation)= 1

(Nursing education) AND (basic life support) AND (simulation training) $=18$ 
(Undergraduate nursing student) AND (nursing) AND (cardiopulmonary resuscitation) AND (basic life support)=6

Base de dados 4: CINAHL (Busca avançada)

(Nursing education) AND (basic life support) AND (simulation training) $=18$

(Validation study) AND (basic life support) AND (simulation training) AND (nursing education) $=0$

(Undergraduate nursing student) AND (nursing) AND (cardiopulmonary resuscitation) AND (basic life support) $=2$

Base de dados 5: Scopus (Elsevier)

(Nursing education) AND (basic life support) AND (simulation training) $=4$

(Validation study AND (basic life support) AND (simulation training) AND (nursing education)=0

Base de dados 6: Embase

(Nursing education) AND (basic life support) AND (simulation training) $=8$

(Validation study) AND (basic life support) AND (simulation training) AND (nursing education) $=0$

(Undergraduate nursing student) AND (nursing) AND (cardiopulmonary resuscitation) AND (basic life support)=2

Base de dados 7: Cochrane

(Nursing education) AND (basic life support) AND (simulation training) $=0$

(Validation study) AND (basic life support) AND (simulation training) AND (nursing education) $=0$

(Undergraduate nursing student) AND (nursing) AND (cardiopulmonary resuscitation) AND (basic life support) $=1$

Base de dados 8: Web of Science

(Nursing education) AND (basic life support) AND (simulation training) $=5$

(Undergraduate nursing student) AND (nursing) AND (cardiopulmonary resuscitation) AND (basic life support) $=5$

4. Critério de inclusão

População: artigos que utilizaram estratégias de ensino para o ensino-aprendizagem de Suporte Básico de Vida a graduandos de enfermagem.

Intervenção: utilização de estratégias de ensino para o ensino de Suporte Básico de Vida a graduandos de enfermagem.

Comparação: utilização de estratégias tradicionais para ensino-aprendizagem de Suporte Básico de Vida a graduandos de enfermagem.

Resultados: metodologias de ensino adequadas para o ensino- aprendizagem de Suporte Básico de Vida a graduandos de enfermagem

4) Critérios de inclusão e exclusão:

Artigos completos, com resumos disponíveis e relacionados ao objeto de pesquisa, nos idiomas Português, Inglês e Espanhol. Foram excluídos artigos oriundos de revisões, editoriais, resumo de anais, relato de experiência, e de ensino em outra área de atuação. e aqueles que não estavam disponíveis na íntegra nas bases de dados, no Portal de Periódicos da Coordenação de Aperfeiçoamento de Pessoal de Nível Superior (CAPES). Os artigos que se repetiram, entre as bases foram considerados apenas uma vez.

5) Extração dos dados:

Os trabalhos selecionados foram lidos na íntegra por dois pesquisadores, momento no qual foram extraídas informações relacionadas a estratégias de ensino e impacto no ensino-aprendizagem do Suporte Básico de Vida a graduandos de enfermagem. As discordâncias entre os resultados extraídos foram resolvidas por consenso, com a presença de um terceiro pesquisador. As informações extraídas foram dispostas em um banco de dados.

6) Síntese das informações:

Cada estudo foi analisado buscando identificar as estratégias de ensino e o impacto do ensino-aprendizagem do Suporte Básico de Vida a graduandos de enfermagem. Busca-se identificar as estratégias e os impactos do ensino de Suporte Básico de vida na graduação em Enfermagem.

Fonte: Autores, a partir das considerações do The Joanna Briggs Institute, Reviewers Mannual (2014).

O processo de seleção dos estudos foi realizado através da leitura dos títulos e resumos inicialmente, e, aqueles que tinham relação com a temática, foram lidos em sua totalidade. Quando respondiam à questão da pesquisa, foram incluídos no estudo, conforme ilustrado na Figura 1. 
Figura 1 - Fluxograma da seleção dos estudos segundo as recomendações do Preferred Reporting Items for Systematic Reviews and Meta-Analyses - PRISMA.

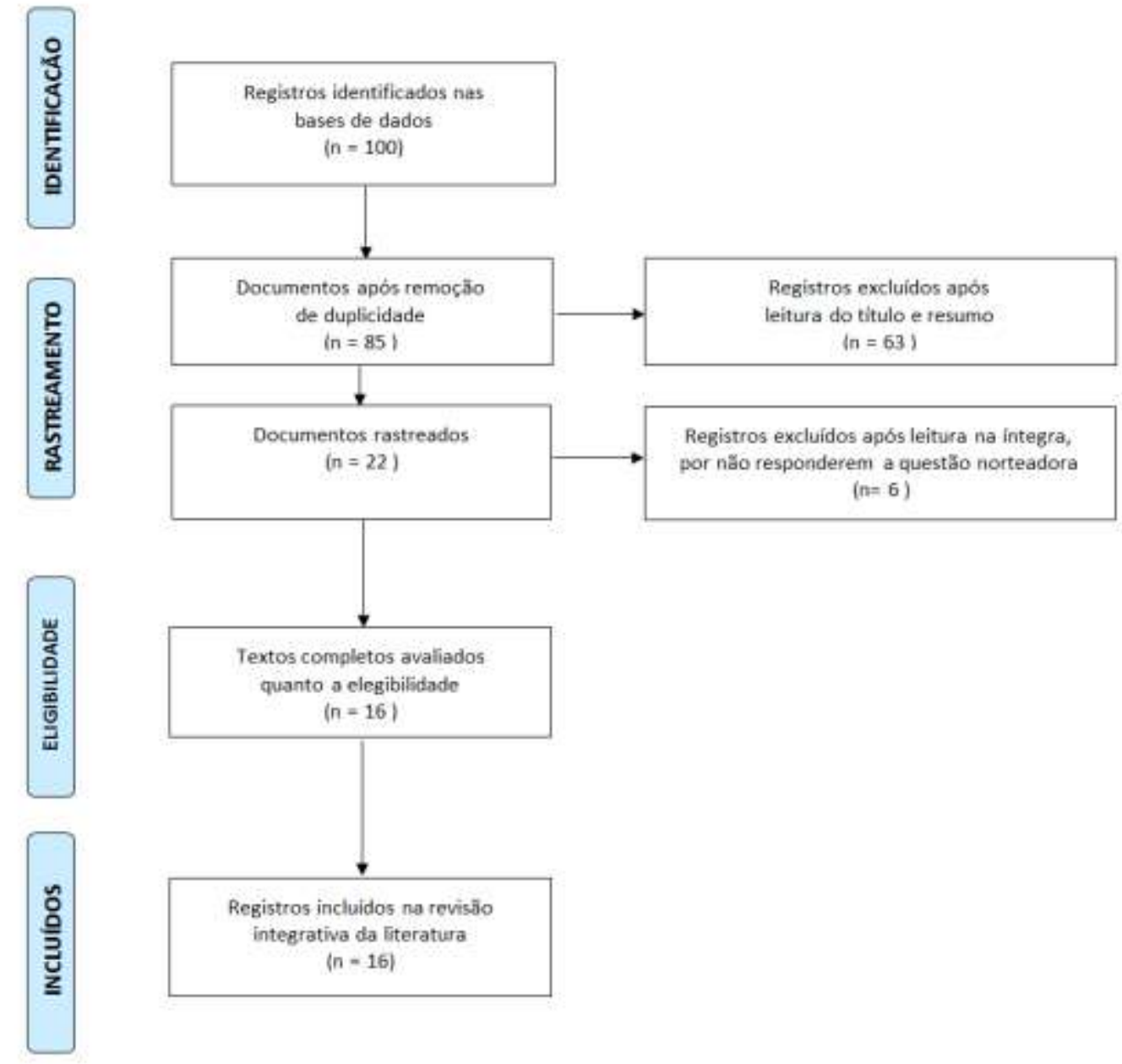

Fonte: Autoras.

\section{Resultados}

Nesta revisão integrativa foram analisados 16 artigos que atenderam aos critérios estabelecidos pelo protocolo. Todos de autoria de enfermeiros e publicados no período entre os anos de 2016 e 2021.

Quanto à indexação dos artigos nas bases de dados, seis (37,5\%) estão na LILACS, quatro (25\%) na Pubmed, quatro (25\%) na CINAHL, um na Scielo (6,25\%), um na Scopus (6,25\%). Nas demais bases, Embase, Cochrane Web of Science não foram encontrados artigos que respondessem à questão da revisão.

Sobre o delineamento de pesquisa dos artigos selecionados encontrou-se um estudo de coorte $(6,25 \%)$ (Roel \& Bjork, 2020), sete (43,75\%) quase experimental (Kose , Mendi \& Goktas; Barbosa et al., 2019; Kim, 2018; Tobase et al., 2017; Johnson et al., 2016; Partiprajak \& Thongpo, 2016), dois (12,5\%) (Alves et al., 2019; Tobase et al., 2018) de produção tecnológica, um experimental (6,25\%) Smereka et al., 2019), um metodológico (6,25\%) (Costa, Tibúrcio, Dantas, Galvão \&Torres, 2018) e quatro (25\%) randomizados e aleatorizados (Carbogim et al., 2018; Lapucci et al., 2018; Coppens, Verhaege, Van Hecke \& Beeckman, 2017; Tastan et al., 2017).

O Quadro 2 apresenta uma síntese dos estudos incluídos na revisão. 
Quadro 2 - Descrição dos estudos incluídos na revisão segundo autores, ano de publicação, delineamento, participantes, objetivo e contribuições.

\begin{tabular}{|c|c|c|c|c|c|}
\hline $\mathbf{N}^{0}$ & & Delineamento & Participantes & Objetivo & Contribuições \\
\hline 1 & $\begin{array}{l}\text { Roel \& Bjork, } \\
2020\end{array}$ & Coorte & $\begin{array}{l}\text { Estudantes na graduação } \\
\text { em ensino de enfermagem } \\
(\mathrm{N}=142)\end{array}$ & $\begin{array}{l}\text { Comparar o conhecimento e habilidade dos } \\
\text { estudantes de enfermagem em CPR antes e depois de } \\
\text { uma intervenção pedagógica. }\end{array}$ & $\begin{array}{l}\text { Os alunos que assistiram a uma simulação clínica } \\
\text { apresentam notas maiores no pós-teste e melhor } \\
\text { eficiência na compressão torácica. }\end{array}$ \\
\hline 2 & $\begin{array}{c}\text { Alves et al. } \\
2019\end{array}$ & $\begin{array}{l}\text { Pesquisa aplicada, de } \\
\text { produção } \\
\text { tecnológica }\end{array}$ & $\begin{array}{l}\text { Profissionais experts da } \\
\text { área de urgência e } \\
\text { emergência } \\
(\mathrm{N}=16)\end{array}$ & $\begin{array}{l}\text { Desenvolver e validar um instrumento de exame } \\
\text { clínico objetivo estruturado para o cenário de } \\
\text { simulação sobre ressuscitação cardiopulmonar no } \\
\text { adulto em suporte básico de vida com o uso do } \\
\text { desfibrilador externo automático no ambiente } \\
\text { hospitalar }\end{array}$ & $\begin{array}{l}\text { O exame clínico objetivo estruturado (OSCE) é uma } \\
\text { atividade contemporânea e adequada ao ensino de } \\
\text { ressuscitação cardiopulmonar em suporte básico de } \\
\text { vida. }\end{array}$ \\
\hline 3 & $\begin{array}{c}\text { Smereka et al. } \\
2019\end{array}$ & Estudo experimental & $\begin{array}{l}\text { Estudantes de graduação } \\
\text { de enfermagem } \\
(\mathrm{N}=94)\end{array}$ & $\begin{array}{l}\text { Avaliar o papel do dispositivo } \begin{array}{r}\text { TrueCPR } \\
\text { pM }\end{array} \text { no } \\
\text { processo de ensinar CPR em } \text { estudantes } \\
\text { enfermagem }\end{array}$ & $\begin{array}{l}\text { A utilização do TrueCPR }{ }^{\mathrm{TM}} \text {, dispositivo de retorno de } \\
\text { ressuscitação cardiopulmonar, permite medir a } \\
\text { profundidade das compressões torácicas, é um } \\
\text { instrumento que contribui na eficácia e conforto dos } \\
\text { alunos durante a simulação clínica de RCP. }\end{array}$ \\
\hline 4 & $\begin{array}{c}\text { Kose et al. } \\
2019\end{array}$ & Quase experimental & $\begin{array}{l}\text { Estudantes de graduação } \\
\text { de enfermagem } \\
(\mathrm{N}=65)\end{array}$ & $\begin{array}{l}\text { Avaliar a eficácia do treinamento básico em suporte à } \\
\text { vida sobre os conhecimentos e práticas dos estudantes } \\
\text { de enfermagem }\end{array}$ & $\begin{array}{l}\text { Treinamento oferecido aos estudantes melhorou o } \\
\text { conhecimento e as habilidades práticas relacionadas ao } \\
\text { Suporte Básico à Vida no pós-teste. }\end{array}$ \\
\hline 5 & Barbosa et 2019 & Quase experimental & $\begin{array}{l}\text { Estudantes de graduação } \\
\text { de enfermagem } \\
(\mathrm{N}=32)\end{array}$ & $\begin{array}{l}\text { Verificar a eficácia da simulação na autoconfiança de } \\
\text { estudantes de enfermagem para ressuscitação } \\
\text { cardiopulmonar extra-hospitalar. }\end{array}$ & $\begin{array}{l}\text { A simulação do atendimento a uma parada } \\
\text { cardiorrespiratória intra-hospitalar promoveu ganhos na } \\
\text { autoconfiança dos estudantes de enfermagem para } \\
\text { atuação em emergência. }\end{array}$ \\
\hline 6 & Kim, 2018 & Quase experimental & $\begin{array}{l}\text { Estudantes de graduação } \\
\text { de enfermagem } \\
(\mathrm{N}=76)\end{array}$ & $\begin{array}{l}\text { Investigar os efeitos do ensino de simulação na } \\
\text { autoeficácia e pensamento crítico dos estudantes de } \\
\text { enfermagem em situações de parada cardíaca de } \\
\text { emergência }\end{array}$ & $\begin{array}{l}\text { Este estudo utilizou a dramatização em ambiente } \\
\text { clínico e palestra. O grupo que passou primeiro por } \\
\text { palestra e após simulação, teve melhor resultado após } \\
\text { simulação. Nenhuma diferença estatisticamente } \\
\text { significante foi encontrada entre os dois grupos. }\end{array}$ \\
\hline 7 & $\begin{array}{l}\text { Carbogim et al. } \\
2018\end{array}$ & Randomizado & $\begin{array}{l}\text { Estudantes de graduação } \\
\text { de enfermagem } \\
(\mathrm{N}=108)\end{array}$ & $\begin{array}{l}\text { Comparar a eficácia da Aprendizagem Baseada em } \\
\text { Problemas (PBL) versus PBL associado ao Modelo } \\
\text { de Aprendizagem Ativa para o Pensamento Crítico } \\
\text { (ALMCT), para melhorar o pensamento crítico (CT) } \\
\text { em estudantes de enfermagem em uma intervenção } \\
\text { educacional no Suporte Básico de Vida (SBV). }\end{array}$ & $\begin{array}{l}\text { A associação de Aprendizagem baseada em Problema } \\
\text { (PBL) e o Modelo de Aprendizagem Ativa para o } \\
\text { Pensamento Crítico (ALMCT) em BLS mostra melhor } \\
\text { aprendizagem. }\end{array}$ \\
\hline 8 & $\begin{array}{l}\text { Lapucci et al. } \\
2018\end{array}$ & Randomizado & $\begin{array}{l}\text { Estudantes de graduação } \\
\text { de enfermagem } \\
(\mathrm{N}=60)\end{array}$ & $\begin{array}{l}\text { Avaliar a validade do método de duas etapas no caso } \\
\text { da } \\
\text { Verificar se dois segundos interrupções periódicas a } \\
\text { cada trinta compressões torácicas permitem o } \\
\text { calongada. }\end{array}$ & $\begin{array}{l}\text { Ensinado a ressuscitação cardiopulmonar com } 4 \\
\text { minutos de compressão torácica contínua e o grupo } \\
\text { controle } 4 \text { minutos de compressões torácicas e com } \\
\text { pausa de } 2 \text { segundos para frequência respiratória. Não }\end{array}$ \\
\hline
\end{tabular}




\begin{tabular}{|c|c|c|c|c|c|}
\hline & & & & $\begin{array}{l}\text { socorrista manter uma massagem cardíaca eficaz por } \\
\text { um longo tempo, independentemente das ventilações } \\
\text { são realizados ou não.Verificar se um sistema de } \\
\text { feedback sobre a eficácia das compressões torácicas } \\
\text { (Habilidade-meter®) tem influência positiva sobre a } \\
\text { eficácia da massagem. }\end{array}$ & há diferença significativa no ensino nos dois grupos. \\
\hline 9 & Costa et al. 2018 & Metodológico & $\begin{array}{l}\text { Juízes especialistas nas } \\
\text { áreas de Enfermagem e } \\
\text { Medicina } \\
(\mathrm{N}=6)\end{array}$ & $\begin{array}{l}\text { Validar o conteúdo de um objeto virtual de } \\
\text { aprendizagem no formato de jogo educativo } \\
\text { simulado, tipo Role Playing Game, sobre Suporte } \\
\text { Básico de Vida para acadêmicos e profissionais de } \\
\text { saúde }\end{array}$ & $\begin{array}{l}\text { O desenvolvimento de um jogo objeto virtual de } \\
\text { aprendizagem (OVA) com as etapas sequenciais de } \\
\text { atendimento ao BLS pode permitir vivencia em } \\
\text { situação real. O jogo foi considerado excelente } \\
\text { conteúdo como objeto de aprendizado virtual. }\end{array}$ \\
\hline 10 & $\begin{array}{l}\text { Coppens et al. } \\
2017\end{array}$ & $\begin{array}{l}\text { Randomizado } \\
\text { controlado }\end{array}$ & $\begin{array}{l}\text { Estudantes de graduação } \\
\text { de enfermagem } \\
(\mathrm{N}=116)\end{array}$ & $\begin{array}{l}\text { Investigar se integrar um curso sobre princípios de } \\
\text { gestão em resolução de conflitos em equipe e } \\
\text { debriefings no treinamento de simulação, aumenta a } \\
\text { auto eficácia, a eficácia da equipe e habilidades } \\
\text { técnicas dos estudantes de enfermagem em cenários } \\
\text { de ressuscitação; II- se as fases contribuem mais com } \\
\text { esses resultados. }\end{array}$ & $\begin{array}{l}\text { A implementação de um curso de gestão de conflitos } \\
\text { em equipe aumentou a auto eficácia e a eficácia da } \\
\text { atuação em equipe na RCP. }\end{array}$ \\
\hline 11 & $\begin{array}{c}\text { Tastan et al. } \\
2017\end{array}$ & $\begin{array}{l}\text { Randomizado } \\
\text { controlado }\end{array}$ & $\begin{array}{l}\text { Estudantes de graduação } \\
\text { de enfermagem } \\
(\mathrm{N}=75)\end{array}$ & $\begin{array}{l}\text { Avaliar os efeitos da música no desempenho } \\
\text { apropriado da taxa e profundidade da compressão } \\
\text { torácica em estudantes de enfermagem. }\end{array}$ & $\begin{array}{l}\text { A utilização da música Stayin 'Alive' Bee Gees } \\
\text { modificada com darbuka turco melhora a taxa de } \\
\text { compressões torácicas. Com a presença da música os } \\
\text { alunos mantem o ritmo (100-120) e até maior que } 121 \\
\text { compressões por minuto. A memória musical contribui } \\
\text { no ritmo das compressões torácicas. }\end{array}$ \\
\hline 12 & $\begin{array}{l}\text { Tobase et al. } \\
\quad 2017\end{array}$ & Quase experimental & $\begin{array}{ll}\text { Estudantes } & \text { de } \\
\text { Enfermagem }(\mathrm{N}=62) & \end{array}$ & $\begin{array}{l}\text { Avaliar o aprendizado de estudantes no curso online } \\
\text { sobre suporte básico de vida com dispositivos de } \\
\text { retroalimentação imediata, em simulação de } \\
\text { atendimento em parada cardiorrespiratória. }\end{array}$ & $\begin{array}{l}\text { A realização de curso online SBV contribuiu no } \\
\text { aumento da nota média no pós-teste, } \\
\text { independentemente do ano de curso dos estudantes. } \\
\text { Contribui para o acesso ao conhecimento, raciocínio } \\
\text { clínico e tomada de decisão. }\end{array}$ \\
\hline 13 & $\begin{array}{c}\text { Tobase et al. } \\
2018\end{array}$ & $\begin{array}{l}\text { Estudo descritivo de } \\
\text { produção } \\
\text { tecnológica }\end{array}$ & $\begin{array}{l}\text { Enfermeiros- }(\mathrm{N}=12) \\
\text { Estudantes de graduação } \\
\text { de enfermagem- }(\mathrm{N}=60)\end{array}$ & $\begin{array}{l}\text { Desenvolver e avaliar o curso on-line sobre Suporte } \\
\text { Básico de Vida, norteado pelo modelo ADDIE como } \\
\text { referencial metodológico no design instrucional, } \\
\text { proposto para desenvolvimento de cursos presenciais } \\
\text { e em ambientes virtuais de aprendizagem. }\end{array}$ & $\begin{array}{l}\text { Curso online sobre SBV utilizando o ADDIE Model } \\
\text { (Analysis, Design, Development, Implementation, } \\
\text { Evaluation), mostrou maior pontuação no pós-teste aos } \\
\text { alunos que participaram do curso. Curso foi avaliado } \\
\text { por especialistas e foi considerado de boa qualidade. } \\
\text { Os alunos que realizaram o curso relatam que se } \\
\text { sentiam seguros para atender SBV após o curso. }\end{array}$ \\
\hline 14 & $\begin{array}{c}\text { Tobase et al. } \\
2017\end{array}$ & Quase experimental & $\begin{array}{l}\text { Estudantes de graduação } \\
\text { de enfermagem } \\
(\mathrm{N}=62)\end{array}$ & $\begin{array}{l}\text { Descrever os resultados de aprendizagem entre os } \\
\text { estudantes de graduação em enfermagem, após um } \\
\text { curso online de BLS (e-BLS). }\end{array}$ & $\begin{array}{l}\text { Alunos realizaram curso online de SBV e aplicaram na } \\
\text { prática. } 93,5 \% \text { dos alunos consideram autoconfiantes } \\
\text { para atendimento de SBV. Os resultados do estudo } \\
\text { mostram que os alunos foram capazes de desenvolver }\end{array}$ \\
\hline
\end{tabular}


Research, Society and Development, v. 10, n. 9, e47310918325, 2021

(CC BY 4.0) | ISSN 2525-3409 | DOI: http://dx.doi.org/10.33448/rsd-v10i9.18325

\begin{tabular}{|c|c|c|c|c|c|}
\hline & & & & & as Diretrizes de RCP pós o curso online. \\
\hline 15 & $\begin{array}{c}\text { Johnson et al. } \\
2016\end{array}$ & Quase experimental & $\begin{array}{l}\text { Pessoal de Enfermagem, } \\
\text { alunos de enfermagem e } \\
\text { medicina } \\
(\mathrm{N}=150)\end{array}$ & $\begin{array}{l}\text { Investigar o uso de um manequim automatizado em } \\
\text { treinamento que fornece feedback imediato sobre os } \\
\text { vários aspectos de RCP, incluindo a taxa de } \\
\text { compressão no peito e a profundidade e a taxa de } \\
\text { ventilação e de volume em certificação de RCP } \\
\text { hospitalar. E determinar se o feedback deste } \\
\text { dispositivo pode trazer a equipe a um nível } \\
\text { considerado competente em um curto treinamento em } \\
\text { habilidades psicomotoras. }\end{array}$ & $\begin{array}{l}\text { Treinamento de curta duração em compressão torácica, } \\
\text { utilizando o manequim Laerdal Resusci-Anne } \\
\text { QCPR }^{\mathrm{TM}} \text {, contribui para habilidades } \\
\text { mostra melhor preparo dos participantes. }\end{array}$ \\
\hline 16 & $\begin{array}{l}\text { Partiprajak \& } \\
\text { Thongpo } \\
2016\end{array}$ & Quase experimental & $\begin{array}{l}\text { Estudantes de graduação } \\
\text { de enfermagem } \\
(\mathrm{N}=30)\end{array}$ & $\begin{array}{l}\text { Examinar a retenção do conhecimento BLS, auto } \\
\text { eficácia e desempenho em compressão torácica de } \\
\text { estudantes de graduação em enfermagem tailandeses } \\
\text { ao realizar um curso de BLS em três fases, pré-teste, } \\
\text { imediatamente pós-teste e pré-teste em } 3 \text { meses após } \\
\text { o treino }\end{array}$ & $\begin{array}{l}\text { Aplicação de palestra de } 1 \text { hora de teoria sobre BLS } \\
\text { melhora a compressão torácica dos estudantes no pós- } \\
\text { teste. Após } 3 \text { meses, não houve mudança significativa } \\
\text { no pré-teste. Há necessidade de treinamento e aplicação } \\
\text { constante das habilidades. }\end{array}$ \\
\hline
\end{tabular}

Fonte: Autores. 
Research, Society and Development, v. 10, n. 9, e47310918325, 2021

(CC BY 4.0) | ISSN 2525-3409 | DOI: http://dx.doi.org/10.33448/rsd-v10i9.18325

A maior concentração de artigos (68,75\%) foi em revistas da área clínica e de emergência em medicina e enfermagem, seguida de publicação na área de educação $(31,25 \%)$.

A simulação foi empregada para ensino e avaliação das habilidades específicas do SBV. Empregaram simulações com robóticas (com simuladores de alta e média fidelidade) em 75\% dos estudos, Role Playing, palestras, jogo online, curso online, Exame Clínico Objetivo Estruturado, simulações cênicas (com pacientes padronizados), Aprendizagem baseada em Problema (PBL) e o Modelo de Aprendizagem Ativa para o Pensamento Crítico (ALMCT). Ainda, em relação ao referencial teórico de SBV, dez artigos usaram fundamentação teórica baseada nas diretrizes do American Heart Association (62,5\%); dois artigos europeus basearam no European Resuscitation Council e, dois artigos australianos utilizaram as diretrizes do Australian Resuscitation Council. Quanto às estratégias utilizadas nas simulações, seis $(37,5 \%)$ artigos utilizaram manequins, sendo três de alta fidelidade. Três estudos recorreram ao uso de curso online.

A maioria das simulações foram avaliadas a partir do comparativo entre pré e pós teste. Um estudo utilizou o equipamento TrueCPR ${ }^{\mathrm{TM}}$ que mensura as compressões torácicas (Smereka et al., 2019). Outro estudo sobre autoconfiança no atendimento a PCR, mostra que os alunos são mais confiantes após cenário clínico simulado (Kose et al., 2019). Um artigo resulta em maior raciocínio crítico e auto eficiência após simulação (Barbosa et al., 2019) . Ainda, uma pesquisa mostra melhora do conhecimento cognitivo com associação de Aprendizagem baseada em Problema (PBL) e o Modelo de Aprendizagem Ativa para o Pensamento Crítico (ALMCT) (Kim, 2018). Três artigos foram desenvolvidos com curso teórico online e submetido à simulação clínica, mostrando resultados de maior conhecimento, autoconfiança no atendimento no SBV (Costa et al., 2018; Tastan et al., 2017; Tobase et al., 2017). Também, os artigos apontam o uso do Exame Clínico Objetivo Estruturado, vídeos contribuem significativamente no aprendizado de SBV (Smereka et al., 2019; Lapucci et al., 2018).

As contribuições da simulação para SBV, entre os estudos analisados, foram relacionadas ao aumento do conhecimento; desenvolvimento de habilidades cognitivas, aperfeiçoamento da compressão torácica, do julgamento clínico e resolução de conflito no trabalho em equipe.

\section{Discussão}

Os artigos estudados destacaram a simulação clínica como uma estratégia eficaz para o ensino e aprendizado do SBV em Enfermagem, nos últimos cinco anos. Esta estratégia permite que o indivíduo vivencie uma situação similar à prática por meio de cenários ou simuladores, estimula o uso do raciocínio clínico, a tomada de decisão, gerenciamento de equipe e desenvolvimento de habilidades psicomotoras (Barbosa et al., 2019; Tastan et al., 2017; Johnson et al., 2016).

Estudos mostram resultados satisfatórios no emprego combinado de suporte teórico, baseado no American Heart Association, European Resuscitation Council e Australian Resuscitation Council e uso de simuladores (Smereka et al., 2019; Kim, 2018; Carbogim et al., 2018; Costa et al., 2018; Coppens et al., 2017). Corroborando com a utilização da tecnologia no manejo da PCR, visando a ação rápida, a valorização da formação adequada e de esforços coordenados para aumentar as chances de sobrevivência pós-parada (AHA, 2020).

Um estudo realizado com alunos de enfermagem implementou um curso de gestão de conflitos para equipe com intenção de avaliar a auto eficácia, a eficácia da equipe e habilidades técnicas com a simulação. O estudo encontrou que o estudante é capaz de perceber a auto eficácia, ter melhor desempenho nas habilidades e ser mais eficaz no trabalho em equipe (Costa et al., 2018). Ainda ressalta que a combinação de debrifieng e gestão de conflitos torna o trabalho em equipe mais eficaz. Fato que pode ser aplicado na prática clínica, contribuindo com trabalho interdisciplinar e segurança do paciente. Além 
disso, o uso da simulação de alta fidelidade proporciona maior segurança aos pacientes e favorece o ensino da prática avançada em enfermagem (Tobase et al., 2017).

Junto com a simulação clínica, a ferramenta do Objective and Structured Clinical Examination (OSCE) foi uma estratégia utilizada como método de avaliação para garantir o processo de ensino aprendizado do SBV. Os alunos desenvolveram competências necessárias para o ensino e avaliação, comumente usadas na enfermagem (Alves et al., 2019). Estudo relata que o emprego do OSCE em SBV foi uma estratégia importante para o ensino, permitindo organização, clareza e objetividade (Benbenek et al., 2016).

Ressalta-se também que a simulação deve ser empregada para ensino de habilidades do (SBV), assim como para efetividade da compressão torácica, pois quando efetiva aumenta a sobrevida (AHA, 2015). Dois estudos comprovaram a efetividade do treinamento nas compressões torácicas junto aos alunos de graduação, através da simulação. Com resultados positivos com ou sem dispositivo de avaliação das compressões (Carvalho et al., 2019; Carbogim et al., 2018; Lapucci et al., 2018).

O mesmo aconteceu em outro estudo realizado na Turquia, que observou que o treinamento das compressões torácicas na presença da música Stayin 'Alive' (Bee Gees) modificada com darbuka turca, foi significativamente maior no grupo intervenção, em comparação com o grupo controle. Ao som da música, os alunos mantiveram o ritmo entre 100-120 compressões torácicas/minutos. Os autores ressaltaram que ouvir música durante a educação em RCP ajuda no desenvolvimento da memória mental e também ajuda a encontrar o ritmo durante a RCP (Coppens et al., 2017). O que corrobora com as diretrizes do AHA que compressões torácicas efetivas melhoram a sobrevida (AHA, 2020).

Estudos comprovam que o emprego das tecnologias no ensino ao SBV sustenta o conhecimento para aplicação em simulação real, através de jogo objeto virtual de aprendizagem (OVA) e curso online (Lapucci et al., 2018; Tastan et al., 2017; Tobase et al., 2017; Tobase et al., 2018). A educação à distância se destaca na atualidade como modalidade alternativa e diferenciada. Também possui características, linguagem e formato próprios, necessitando de administração, desenho, acompanhamento, avaliação, tecnologia e recursos pedagógicos condizentes para potencializar o processo educativo, ampliando o alcance e a abrangência da educação (Kim, 2018).

Frente à complexidade da parada cardiorrespiratória, a simulação mostra-se como ferramenta adequada para o ensino destas habilidades, por ser dinâmica, fornecendo uma visão real das situações clínicas dentro de um ambiente protegido e controlado.

A presente revisão teve como limitações a dificuldade de encontrar os descritores que combinados apresentassem resultados de simulação em Cursos de Graduação em Enfermagem e o restrito número de estudos com delineamento de pesquisa que resultam em resultados com forte evidência. No entanto, os achados apresentados responderam à questão norteadora, que era de conhecer como a simulação da prática clínica tem sido utilizada para o ensino aprendizado do SBV no Curso de Graduação de Enfermagem.

\section{Conclusão}

A simulação da prática clínica em SBV contribui no processo de ensino aprendizagem para os alunos dos Cursos de Graduação em Enfermagem, através do melhor reconhecimento da parada cardiorrespiratória, compressões torácicas efetivas, desfibrilação precoce, desenvolvimento de competências de manejo clínico avançado, incluindo as habilidades de trabalho em equipe e tomada de decisão. 
Research, Society and Development, v. 10, n. 9, e47310918325, 2021

(CC BY 4.0) | ISSN 2525-3409 | DOI: http://dx.doi.org/10.33448/rsd-v10i9.18325

Além de impactar no preenchimento de lacunas do aprendizado, estimula o uso das evidências científicas e o desenvolvimento do raciocínio clínico. Foi evidenciada que a simulação da prática clínica é uma ferramenta eficaz para ensino de SBV, favorecendo o ensino da prática em enfermagem e proporcionando maior segurança aos alunos durante a assistência.

Como sugestão de trabalhos futuros acerca deste tema, propõe-se que a simulação clínica no processo de ensinoaprendizagem da Enfermagem, no sentido de avaliar a eficácia do emprego da metodologia pelos docentes, tornando a aprendizagem mais significativa.

\section{Referências}

Alves M. G., Carvalho M. T. M., Nascimento J. S. G., Oliveira J. L. G., Cyrillo R. M. Z, Braga F. T. M. M., Fonseca L. M. M. \& Darli M. C. B. (2019). Construction and validation of objective structured clinical examination (OSCE) on cardiopulmonary resuscitation. Rev Min Enferm, 23 , 1-9.

American Heart Association. (2020). Adult Basic Life Support International Consensus on Cardiopulmonary Resuscitation and Emergency Cardiovascular Care Science With Treatment. Recommendations. Circulation, 142(suppl 1), S41-S91.

American Heart Association (2015). Guidelines Update for Cardiopulmonary Resuscitation and Emergency Cardiovascular. Circulation, S561-S573.

Barbosa G. S., Bias C. G. S., Agostinho L. S., Oberg L. M. C. Q., Lopes R. O. P. \& Souza R. M. C. (2019). Eficácia da simulação na autoconfiança de estudantes de enfermagem para ressuscitação cardiopulmonar extra-hospitalar: um estudo quase experimental. Scientia Medica, 29(1), 32694-32694.

Benbenek M., Dierich M., Wyman J., Avery M., Juve C. \& Miller J. (2016). Development and Implementation of a Capstone Objective Structured Clinical Examination in Nurse Practitioner and Nurse-Midwifery Programs. J Nurs Educ, 41(6), 288-293.

Broome M. E. (2000). Integrative literature reviews for the development of concepts. Concept development in nursing: foundations Techniques and Applications. Saunders Company, 231-50.

Carbogim F. C, Barbosa A. C. S., Oliveira L. B, Diaz F. B. B. S., Toledo L. V., Alves K. R., Friedrich D. B. C., Luiz F. S. \& Püshel V. A. A. (2018). Educational intervention to improve critical thinking for undergraduate nursing students: a randomized clinical trial. Nurse Educ. Pract, 33 , $121-126$.

Coppens I., Verhaege S., Van Hecke A., Beeckman D. (2017). The effectiveness of crisis resource management and team debriefing in resuscitation education of nursing students: a randomised controlled trial. J Clin Nurs, 27(1-2), 77-85.

Costa I. K. F., Tibúrcio M. P., Dantas R. A. N., Galvão R. N., Torres G. V. (2018). Development of a virtual simulation game on basic life support. Rev. esc. enferm. USP, 52, 1-8.

French A. J. (2020). Simulation and Modeling Applications in Global Health Security. Global Health Security, 307-340.

Joanna Briggs Institute (2014). Reviewers’ Manual. https://nursing.lsuhsc.edu/JBI/docs/ReviewersManuals/Economic.pdf

Johnson M., Peat A., Boyd L., Warren T., Eastwood, K \& Smith G. (2016). The impact of quantitative feedback on the performance of chest compression by basic life support trained clinical staff. Nurse Education Today, 45, 163-6.

Kim E. (2018). Effect of simulation-based emergency cardiac arrest education on nursing students' self-efficacy and critical thinking skills: roleplay versus lecture. Nurse Education Today, 61, 258-263.

Kose S., Akin S., Mendi O. \& Goktas S. (2019). The effectiveness of basic life support training on nursing students' knowledge and basic life support practices: a non-randomized quasi-experimental study. Afr Health Sci, 19(2), 2252-2262.

Lapucci G., Bondi B., Rubbi .I, Cremonini V., Moretti E., Di Lorenzo R., Magnani D. \& Ferri P. (2018). A randomized comparison trial of two and four-step approaches to teaching cardio-pulmonary reanimation. Acta Biomed, 89, 37-44.

Mendes K. S., Silveira R. C. C. P. \& Galvão C. M. (2008). Revisão integrativa: método de pesquisa para a incorporação de evidências na saúde e na enfermagem. Texto \& contexto enfermagem, 17(4), 758-764.

Moher D., Shamseer L., Clarke M., Ghersi D., Liberati A., Petticrew M., Shekelle P., Stewart L. A. (2021). Preferred reporting Items for Systematic Review and Meta-Analysis Protocols (PRISMA-P). https://www.bmj.com/content/349/bmj.g7647 .

Partiprajak S. \& Thongpo, P. (2016). Retention of basic life support knowledge, self-efficacy and chest compression performance in Thai undergraduate nursing students. Nurse Educ. Pract, 16(1), 235-241.

Ribeiro V. S., Garbuio D. C., Zamariolli C. M., Eduardo A. H. A., Carvalho E. C. (2018). Simulação clínica e treinamento para as Práticas Avançadas de Enfermagem: revisão integrativa. Acta Paul Enferm, 31(6), 659-666.

Roel S., Bjork, I. T. (2020). Comparing Nursing Student Competence in CPR before and after a Pedagogical Intervention. Nursing Research and Practice, 1-6.

Smereka J.., Szarpak L., Czekajlo M., Abelson A., Zwolinski P., Plusa T., Dunder D., Drabrowski D., Wiesnewska Z, Robak O., Frass M., Sivrikaya U. G. \& Ruetzler K. (2019). The TrueCPR device in the process of teaching cardiopulmonary resuscitation. Medicine, 98(2), 1-7. 
Research, Society and Development, v. 10, n. 9, e47310918325, 2021

(CC BY 4.0) | ISSN 2525-3409 | DOI: http://dx.doi.org/10.33448/rsd-v10i9.18325

Sociedade Brasileira de Cardiologia (2019). Atualização da Diretriz de Ressuscitação Cardiopulmonar e Cuidados Cardiovasculares de Emergência da Sociedade Brasileira de Cardiologia. Arq Bras Cardiol, 113(3), 449-663.

Tastan S., Ayhan H., Unver V., Cinar F.I., Kose G., Basak T. et al. (2017) The effects of music on the cardiac resuscitation education of nursing students. Int Emerg Nurs, 31, 30-35.

Tobase L., Peres H. C., Almeida D. M., Tomazini E. A. S., Ramos M. B. \& Polastri T. F. (2018). Instructional design in the development of an online course on Basic Life Support. Rev. esc. enferm. USP, 51, 309-13.

Tobase L., Peres H. C., Gianotto-Oliveira R., Smith N., Polastri T. F. \& Timerman S. (2017). The effects of an online basic life support course on undergraduate nursing students' learning. Int J Med Educ, 8, 309-13.

Tobase L., Peres H. C., Tomazini E. A. S., Teodoro S. V., Ramos MB, \& Polastri T. F. (2017). Suporte básico de vida: Avaliação da aprendizagem com uso de simulação e dispositivos de feedback imediato. Rev Lat Am Enfermagem, 25-29. 